\title{
Long-Term Persistence of Anti-SARS-COV-2 IgG Antibodies
}

\author{
Zahra Yousefi ${ }^{1} \cdot$ Niloofar Taheri $^{2} \cdot$ Motahareh Dargahi $^{2} \cdot$ Reza Chaman $^{3} \cdot$ Ehsan Binesh $^{4}$. \\ Mohammad Hassan Emamian ${ }^{5} \cdot$ Reza Jafari $^{1}$ [D
}

Received: 24 July 2021 / Accepted: 2 February 2022 / Published online: 12 February 2022

(c) The Author(s), under exclusive licence to Springer Science+Business Media, LLC, part of Springer Nature 2022

\begin{abstract}
Antibodies against severe acute respiratory syndrome coronavirus-2 (Anti-SARS-COV-2) can be detected in patients with COVID-19 in 7 to 10 days post onset of symptoms (POS). However, there is no firm evidence of the long-term persistence of these antibodies in recovered COVID-19 patients. Therefore, this study aimed to evaluate the stability of anti-SARSCOV-2 IgG in recovered COVID-19 patients in a 15-month follow-up testing. Thirty hospitalized patients with real-time PCR-confirmed SARS-COV-2 infections were included in the study and five serum samples (1st, 2nd, 3rd, 4th, and 5th) were collected from each participant. The serum levels of $\mathrm{N}$ and $\mathrm{S}$ specific anti-SARS-COV-2 IgG and IgM antibodies were evaluated by the immunoassay technique at the same time. To determine the correlation between levels of anti-SARS-CoV-2 IgG/IgM with severity of disease, neutrophil-to-lymphocyte ratio (NLR \%), and the serum levels of C-reactive protein were evaluated using an automated analyzer and turbidimetry assays, respectively. The mean serum level of anti-SARS-CoV-2 $\operatorname{IgG}$ antibody was at the highest level up to 90 days and then decreased significantly 1 year POS $(P<0.0001)$. However, it was still detectable in a 15-month follow-up testing. There were no significant differences in the mean levels of IgG antibody in patients with mild, moderate, and severe diseases. The results from this study suggest that the titer of anti-SARS-COV-2 $\mathrm{IgG}$ antibody is detectable at high levels up to 3 months and then decreases over time. However, these antibodies can be reliably detected in up to 15 months, and they may persist for a long time.
\end{abstract}

\section{Introduction}

Although the COVID-19 pandemic has lasted for more than 20 months, the role of anti-SARS-CoV-2 IgG/IgM in immunity to the disease is still debated. It has been reported that the antibody responses are decreased in several months post onset of symptoms [1,2]. The first study by Zhang et al. showed an increased rate of virus-specific IgM and $\operatorname{IgG}$ in

Reza Jafari

jafari.r@shmu.ac.ir

1 School of Allied Medical Sciences, Shahroud University of Medical Sciences, Shahroud, Iran

2 Student Research Committee, School of Medicine, Shahroud University of Medical Sciences, Shahroud, Iran

3 Department of Community Medicine, School of Medicine, Shahroud University of Medical Sciences, Shahroud, Iran

4 Clinical Research Development Unit, Imam Hossein Hospital, Shahroud University of Medical Sciences, Shahroud, Iran

5 Ophthalmic Epidemiology Research Center, Shahroud University of Medical Sciences, Shahroud, Iran
81 and $100 \%$ of the patients who suffered from COVID-19, respectively, 5 days after admission [3]. Moreover, Li et al., reported that some patients are more seropositive for $\operatorname{IgG}$ than IgM against either nucleocapsid $(\mathrm{N})$ or spike proteins [4]. Another study has demonstrated that most patients with COVID-19 are negative for anti-SARS-CoV-2 IgM antibody while anti-SARS-CoV-2 IgG antibody is positive in $20 \%$ of asymptomatic patients [5].

It has been reported that the specific spike neutralizing antibodies (Nabs) are detectable in COVID-19 patients 10 to 15 days after the POS [6]. Most hospitalized COVID19 patients show a rapid increase in the receptor binding domain (RBD)-specific IgG antibody 6 days post PCR confirmation. However, Ibarrondo et al., have shown that SARS-COV-2-specific antibody responses decrease quicker than SARS-COV-1, 4, 5, suggesting that humoral immunity may not persist in recovered COVID-19 patients. They have also reported that the median duration of persistence of anti-SARS-COV-2 IgG antibody was 168.5 days in healthcare workers [7]. Moreover, Wang et al., observed that plasma levels of the specific spike Nabs were higher in the elderly than young and middle-age patients. This increase 
was negatively correlated with lymphocyte count and positively correlated with plasma CRP levels of the patients [8]. On the other hand, evaluation of the level of anti-SARSCOV-2 specific antibodies in hospitalized patients indicates that intensive care unit (ICU) patients have higher levels of Nabs in comparison to non-ICU patients [9]. It has been established that the neutralizing properties of anti-SARSCoV-2 IgG antibody have a regular pattern, in which antibody increases rapidly within the first 3 weeks and then decreases 6 months after the onset of symptoms [1]. Another study reported that the serum levels of anti-SARS-CoV-2 RBD-specific IgM, IgG, and IgA antibodies were rapidly reduced in serum of convalescent patients 4-14 weeks after discharge [10]. Accordingly, it can be inferred that the production pattern of anti-SARS-COV-2 antibodies in COVID-19 patients is different [11]. However, a longitudinal study reported that recovered patients with both low peak infection dose (ID50 < 10,000) and high peak infective dose (ID50 > 10,000) maintained a titer of SARS-COV-2-neutralizing antibody up to 60 days POS [12]. In addition, Wajnberg et al., have shown that the anti-spike IgG antibody will be stable in individuals with a mild-to-moderate COVID-19 for up to 5 months [13].

However, the studies mentioned above indicate that anti-SARS-COV-2 decrease over time in patients who have recovered from COVID-19; and thus it is necessary to conduct long-term follow-up studies to better understand the process of producing anti-SARS-COV-2 profiles. Therefore, this longitudinal study aimed to clarify the duration or stability of anti-SARS-COV-2 in COVID-19 recovered individuals.

\section{Methods}

\section{Population}

This prospective, single-center study included 30 recovered COVID-19 patients with confirmed real-time PCR of nasopharyngeal and oropharyngeal swabs. The study was approved by the Ethics Committee of Shahroud University of Medical Sciences (No: IR.SHMU.REC. 1399.077). Initially, this was intended to be a short study lasting for 3 months, but due to the prolongation of the COVID-19 pandemic, the patients were followed for 15 months. A written consent form was completed before collecting samples. Peripheral blood samples were collected in 5 days (1st sample), 30 days (2nd sample), 90 days ( 3 rd sample), 365 days (4th sample), and 450 days (5th sample) POS (Supplementary Table 1). Two patients who died during the follow-up period were excluded from the study. Five people who were not available for the 5th sample and three who became vaccinated were excluded as well.

\section{Measurement of C-Reactive Protein (CRP)}

Peripheral blood samples were taken from 28 patients and then serum was collected by centrifuging at $3000 \mathrm{rpm}$, which was kept at $-70{ }^{\circ} \mathrm{C}$ until the time of measurement by CRP turbidimetry Kit (Delta Darman Part LOT, 1701520, Iran). Briefly, distilled water, standard reagent, and serum sample ( $10 \mu \mathrm{l}$ from each) were added into the blank, standard, and sample tubes, respectively. Then, $800 \mu$ of regent 1 (TRIS buffer, PH: 8.2) were added into each tube. The contents were mixed and then incubated for five minutes at $37{ }^{\circ} \mathrm{C} .200 \mu \mathrm{l}$ of reagent 2 (latex particles with IgG Goat, $\mathrm{pH}$ 7.3) were pipetted into each tube and incubated for five minutes at $37^{\circ} \mathrm{C}$. Finally, the standards and samples' optical densities (OD) were measured by an automated analyzer (BT1500, Biotecnica, Italy) at $600 \mathrm{~nm}$ wavelength against a blank tube. The protein concentration of each sample was calculated using a standard curve.

\section{Calculation of Neutrophil to Lymphocyte Ratio (NLR \%)}

Peripheral blood samples collected by a closed-loop system were directly added to K3EDTA and were immediately analyzed by an automated analyzer (ABX Micros ES $60 \mathrm{HOR}-$ IBA, Japan). NLR was determined as absolute neutrophil count divided by absolute lymphocyte count.

\section{Detection of SARS-CoV-2 IgG and IgM Antibodies}

During the 15 months of follow-up, 132 venous blood samples were obtained from all the patients. The serum samples were separated by centrifugation (3000 rpm for $10 \mathrm{~min}$ ) and stored at $-70{ }^{\circ} \mathrm{C}$. Anti-SARS-CoV-2 IgG (Euroimmun, El 2606-9601 G, Germany) and IgM (Pishtazteb, PTCoV-2-IgM cap-96 LOT, 99007) ELISA kits were used to quantitatively detect antibodies. Briefly, serum samples in duplicate were diluted 1:101 in the sample buffer, and $100 \mu \mathrm{l}$ of each of the calibrator, positive, negative controls, and diluted serum samples were transferred into the microplate wells according to the manufacturer's protocol. Then, the microplates were incubated for $60 \mathrm{~min}$ at $37^{\circ} \mathrm{C}$. The wells were washed three times using $300 \mu$ of working-strength wash buffer for each wash. $100 \mu \mathrm{l}$ of enzyme conjugate antihuman IgG were added to each microplate well and incubated for $30 \mathrm{~min}$ at $37^{\circ} \mathrm{C}$. The microplates were washed as described above. $100 \mu \mathrm{l}$ of substrate solution were pipetted into each of the microplate wells and incubated for $30 \mathrm{~min}$ at room temperature $\left(18-25^{\circ} \mathrm{C}\right)$. In a dark place, $100 \mu \mathrm{l}$ of stop solution were added to the microplates, and the OD 
of each sample was determined at $450 \mathrm{~nm}$ and a reference wavelength between 620 and $650 \mathrm{~nm}$ within $30 \mathrm{~min}$. A calibration curve was used to accurately determine the quantitative antibody concentration in relative vitality units (IU/ml).

\section{Statistic Methods}

The repeated measures ANOVA was used to compare the means of the antibody levels during the 15 -month period. The comparison between SARS-CoV-2 IgG antibody and disease severity was performed using one-way ANOVA; and Spearman correlation statistical method was conducted to analyze the correlation between levels of NLR\% or CRP and SARS-CoV-2 IgG antibody levels.

\section{Results}

\section{Patients}

Twenty-eight patients who had recovered from COVID19 were included in the study. Out of 28 patients, $53.6 \%$ were male and $46.4 \%$ were female with a median age of $56.28 \pm 14.95$ and a mean body mass index (BMI) of $56.28 \pm 14.95$. Twenty-five patients $(90 \%)$ had a positive lung CT scan with mild or moderate involvement. The mean length of hospital stay was $5.5 \pm 5$ days. Based on CRP levels and NLR\%, patients were divided into three categories: mild, moderate, and severe. The mean level of CRP was $40.28 \pm 21.40$.

\section{Titers of SARS-CoV-2 IgG and IgM Antibodies}

The titers of $\operatorname{IgG} / \operatorname{IgM}$ antibodies against spike (S) and nucleocapsid $(\mathrm{N})$ proteins were measured simultaneously by enzyme-linked immunosorbent assay (ELISA) technic over multiple time points. The results were evaluated by calculating a ratio of the control or patient sample's OD over the calibrator's OD and were interpreted as follows: Ratio $<0.8$ : negative, ratio $\geq 0.8$ to $<1.1$ : borderline, and ratio $\geq 1.1$ : positive. The titers of anti-SARS-CoV-2 IgG and IgM antibodies were compared in the 1st, 2nd, 3rd, 4th, and 5th samples. The findings showed that the levels of antiSARS-CoV-2 IgG antibody were at their highest level for 3 months (1st, 2nd, and 3rd samples) and then decreased in 15 months (the 5th sample) POS. In contrast, the levels of IgM did not significantly change during this 15 -month period (Fig. 1a). One hundred percent of the patients were seropositive for $\mathrm{IgG}$ up to 3 months following symptom onset and this rate dropped to $84 \%$ after 15 months (Supplementary Table 1). Only one in 28 individuals (3.5\%) did not have detectable IgG antibodies against SARS-COV-2 after 15 months (the 5th sample). There was no significant difference in the levels of anti-SARS-CoV-2 IgG antibody in the 1st, 2nd, and 3rd samples. However, the IgG levels were decreased significantly in the 4 th and 5 th samples compared to the 3rd $(P<0.0001)$ (Fig. 1b). It was also observed in the follow-up tests of the patients that the severity of the disease had no significant effect on the amount of anti-SARS-CoV-2 IgG antibodies (Fig. 1c).

\section{Correlation Between Serum Levels of IgG and CRP}

Figure 2 shows the correlation between CRP and the titer of $\mathrm{IgG}$ in the patients in the mentioned period. There was a weak positive correlation between serum levels of IgG and CRP in the 1st, 2nd, and 3rd samples. However, the amount of CRP was not correlated with the levels of anti-SARSCOV-2 IgM antibody (data are not shown).

\section{Correlation Between Serum IgG and NLR\%}

Additionally, the correlation between NLR\% and IgG was calculated for up to 15 months POS (Fig. 3). Data analysis showed that the serum levels of IgG were positively correlated with NLR\% in the 1st ( $r=0.4253)$, 2nd ( $r=0.2215)$, and 3rd $(r=0.1452)$ samples. This correlation was significant in the 1st sample in contrast to the 2 nd and 3rd samples $(P<0.02)$.

\section{Correlation Between Serum IgM and NLR\%}

To determine the correlation between the titer of IgM and NLR\%, data were analyzed using Spearman correlation statistical method (Fig. 4). The levels of anti-SARS-COV-2 IgM antibody were significantly correlated with NLR\% in the 1st $(P<0.003), 2$ nd $(P<0.003)$, and 3 rd $(P<0.009)$ samples. However, there was no significant correlation between the titer of IgM and NLR\% in the 4th and 5th samples $(P<0.45)$.

\section{Discussion}

It has been proven that the specific antibody responses to SARS-COV-2 decline in patients who recovered from COVID-19 in 3 to 6 months. However, duration and stability of anti-SARS-COV-2 during the COVID-19 pandemic have not been yet determined.

The results from this study showed that SARS-COV-2 IgG antibody is at its highest level in 3 months and positive in $99 \%$ of the patients in 15 months POS. The first report on anti-SARS-COV-2 was published by Zhang et al. (December 2020), which showed that antibodies could be detected in $80 \%$ of the patients up to 1 month after recovery [3]. Furthermore, Li et al., reported that all the patients had 

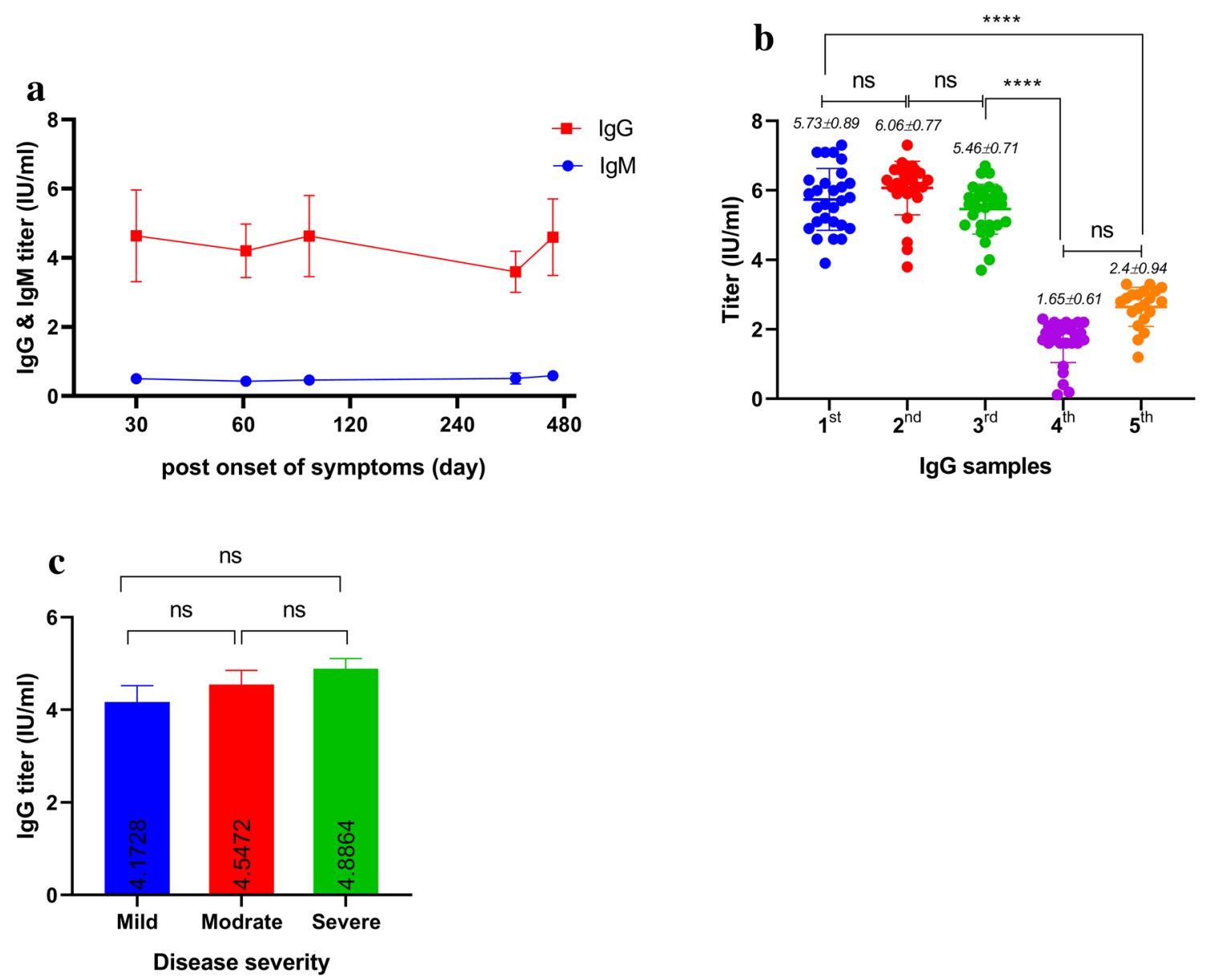

Fig. 1 Concentrations of IgG \& IgM POS. The mean titer of IgM antibodies was increased a few days POS and then remained almost unchanged for up to 15 months in recovered COVID-19 patients. Mean titer of IgG antibodies was decreased over time (a). The titer of serum $\mathrm{IgG}$ antibody was performed in duplicate and the values were significantly higher in the $1 \mathrm{st}, 2 \mathrm{nd}$, and $3 \mathrm{rd}$ samples compared with the 4 th and 5 th samples $(P<0.0001)$. Mean titer of $\operatorname{IgG}$ in the fifteenth month was higher than that of the twelfth month (b). Mean

anti-SARS-COV-2 IgM antibody 10-15 days POS. However, anti-SARS-COV-2 IgG antibody is only stable for a few months after recovery [6]. It seems that depletion of the serum levels of anti-SARS-COV-2 IgG antibody in the early months of the disease may be due to a decrease in memory B cells. De Biasi et al., observed that the number of plasma cells was significantly increased in untreated COVID-19 patients while the numbers of naïve $\mathrm{B}$ cells and memory $B$ cells were decreased [14]. Hence, reduction of memory B cells may lead to a defect in the IgG class switching during COVID-19. These studies and similar studies performed at the beginning of the COVID-19 pandemic suggest that the amount of anti-SARS-COV-2 IgM/IgG antibodies is decreased shortly after recovery. Accordingly, Turner et al., reported that the SARS-COV-2 specific antibody-producing plasma cells in the bone marrow remained stable for a long titer of IgG was not significant in mild, moderate, and severe patients $(P<0.23)(\mathbf{c})$. The repeated measures ANOVA and one-way ANOVA were used to analyze anti-SARS COVID-19 IgG titers and severity of disease, respectively, during the specified period of this study. Data are presented as mean \pm SEM. The findings showed that the levels of SARS-CoV-2 IgG antibody were at their highest level up to 3 months after the onset of symptoms

time in patients who recovered from mild SARS-COV-2 infections [15]. Similarly, it was observed in the present study that a certain amount of anti-SARS-COV-2 IgG antibodies, regardless of sex, age, and BMI, could be detected in the serum of recovered patients up to 15 months. However, the serum levels of $\operatorname{IgG}$ were decreased significantly 1 year POS compared to 3 months. This decreasing trend in antibodies has no significant relationship with the severity of the disease. Surprisingly, the mean levels of IgG antibody in the 5 th samples were increased compared to the 4 th samples $(2.4 \pm 0.94$ vs. $1.65 \pm 0.61)$. It could be due to re-infection or subsequent exposure of the studied COVID-19 subjects.

Sun et al., reported that the decrease of CRP, positively correlates with an increase of spike-IgG antibodies in nonICU patients [16]. Accordingly, it was observed in this work that the amount of CRP has a weak positive correlation with 

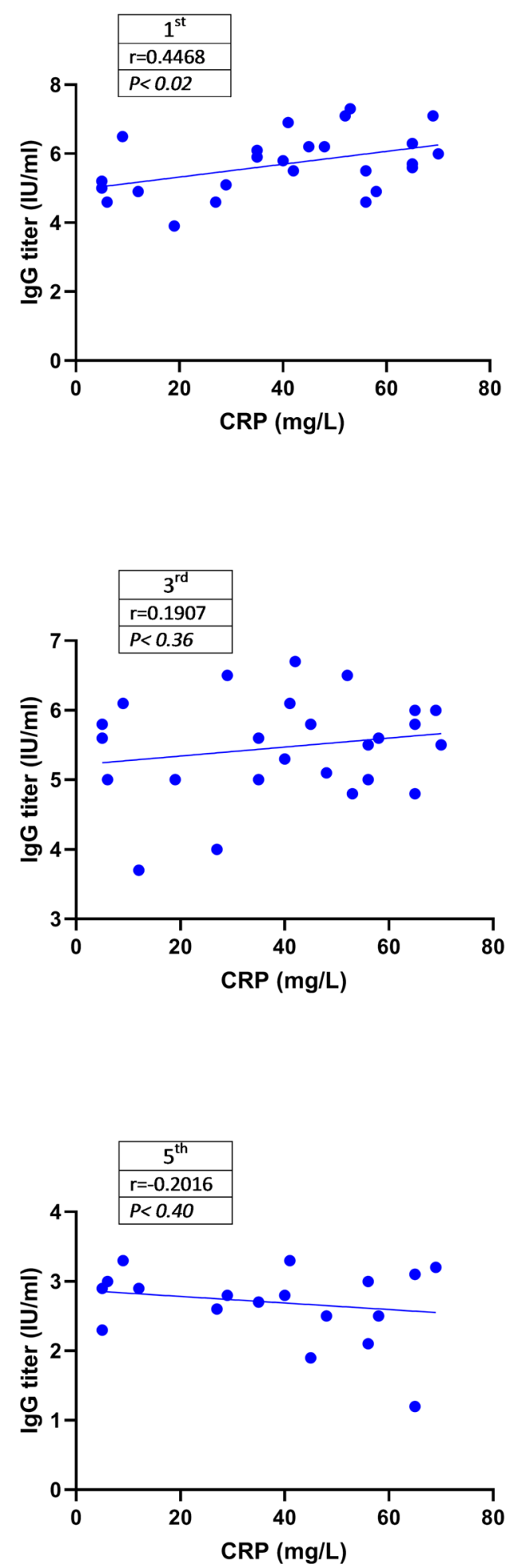

Fig. 2 Correlation Between CRP Concentration and Serum Levels of $\mathrm{IgG}$. The correlation between levels of $\mathrm{IgG}$ and CRP was analyzed using the Spearman statistical method. The serum levels of IgG were positively correlated with serum concentration of CRP in the 1st, 2nd,
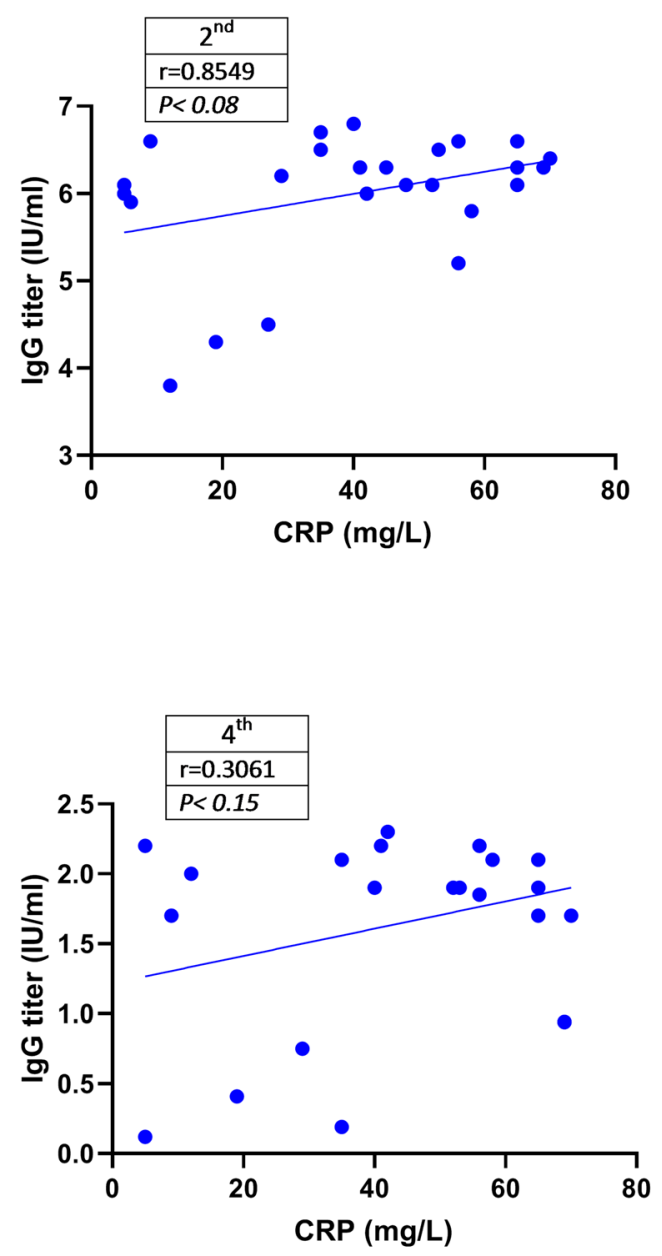

and 3rd samples. This correlation was only significant in the 1st sample $(P<0.02)$. Figure 2 shows the correlation between CRP and IgG titer in the patients over the course of this study 

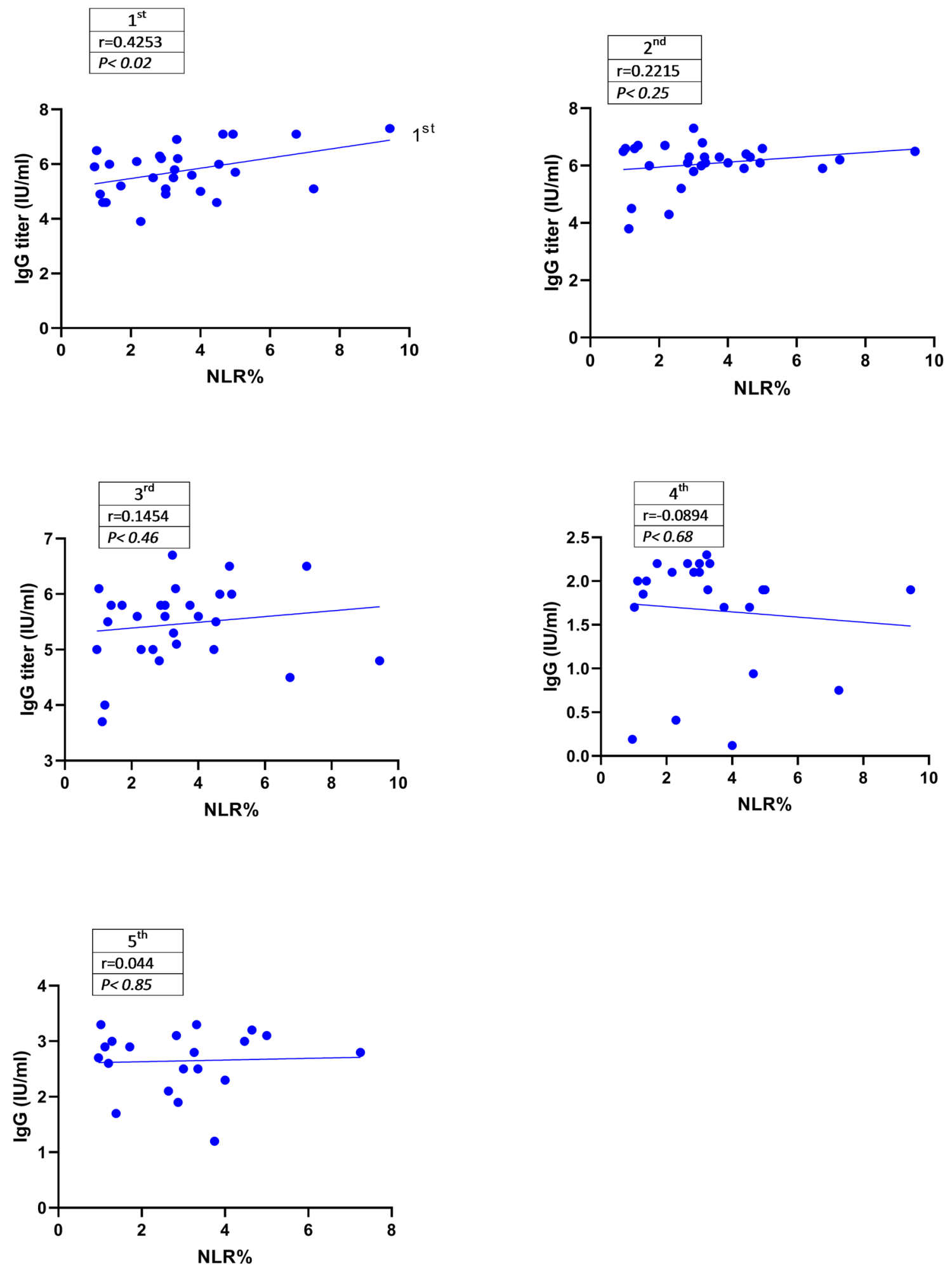

Fig. 3 Correlation Between Percentage of NLR and Serum Levels of IgG. The Spearman statistical analysis method showed that the NLR\% was positively associated with serum levels of IgG at the mentioned points in time. This correlation was significant in the 1 st sam-

ple $(P<0.02)$ but not in the 2 nd, 3 rd, 4 th, and 5 th samples. Moreover, the correlation between NLR\% and IgG was calculated for up to 15 months POS 

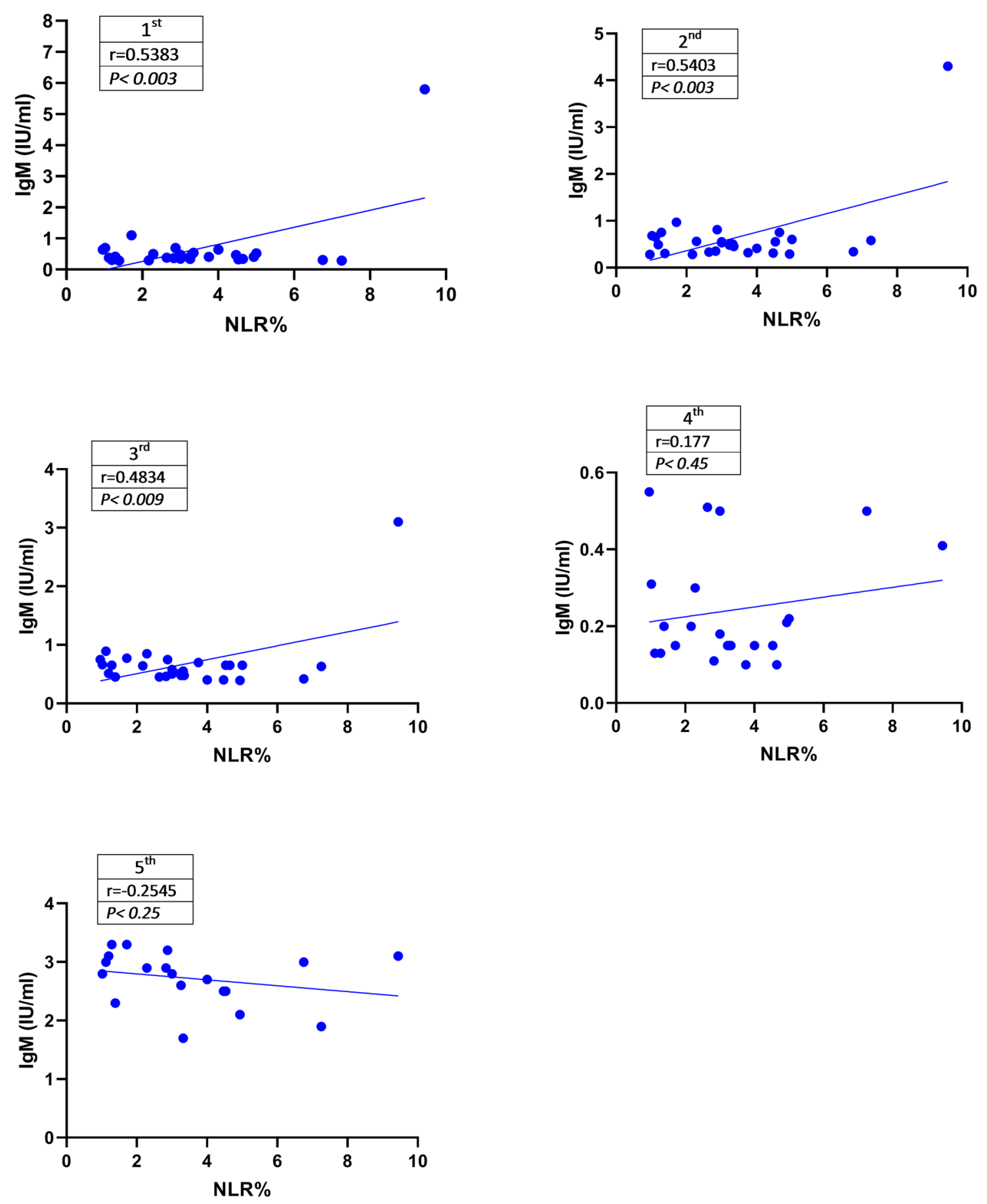

Fig. 4 Correlation between the percentage of NLR and serum levels of IgM. Data analysis using the Spearman statistical method showed a positive and significant correlation between the serum levels of IgM and NLR\% in the 1 st, 2 nd, and 3 rd samples $(P<0.05)$. Data are pre-

sented as mean \pm SEM. To determine the correlation between IgM titer and NLR\%, data were analyzed using Spearman correlation statistical method

virus-specific IgG antibodies. This correlation was significant in the 1st sample compared to the 2nd, 3rd, 4th, and 5th samples (Fig. 2).

On the other hand, studies have revealed that NLR\% is directly associated with the level of anti-SARS-COV-2 and

the severity of COVID-19 [17, 18]. Zhang et al., demonstrated that severe SARS-CoV-2 infection and a high mortality rate were occurred in patients with high NLR\% and low levels of IgG [19]. The results of this study showed that the amounts of anti-SARS-COV-2 IgM antibody were 
significantly associated with NLR\% in the 1st, 2nd, and 3rd samples. Furthermore, the NLR\% in the first month (the 1st sample) had a significant correlation with the level of anti-SARS-COV-2 IgG antibody. However, this correlation was not significant in the $2 \mathrm{nd}, 3 \mathrm{rd}$, 4th, and 5th samples. This may be due to the failure of B-cell differentiation and activation in the early stages of the COVID-19. Accordingly, Kaneko et al., observed that patients with acute SARSCoV-2 infection had a defect in the germinal center's formation and differentiation of BCL6 $+\mathrm{T}$ follicular helper (Tfh) cells due to the high level of TNF- $\alpha$ [20]. In other words, disruption of the germinal centers with a lack of adequate B-cell function may decrease antibody production despite an increase in helper $\mathrm{T}$ cell activity [21]. Therefore, convalescent plasma or interleukin-6 inhibitors such as tocilizumab may be considered for patients with a low level of anti-SARS-COV-2 IgG antibody.

Although the findings of this study showed that some level of anti-SARS-COV-2 IgG antibody is detectable in recovered COVID-19 patients for at least 15 months, there are some limitations to this study such as small sample size and vaccination or death of some of the participants. Moreover, an assay of neutralizing antibodies could help in determining the stability of the immunity post onset of the disease.

\section{Conclusion}

According to the present study's results, despite the decrease in the amount of IgG antibodies over time, protective levels of anti-SARS-COV-2 could sustain for a lifetime in recovered COVID-19 patients. Surprisingly, the detectable level of antibodies was not significantly associated with serum level of CRP or NLR for up to 15 months POS. Therefore, production of antibodies in people who received a COVID19 vaccine may be similar to patients who experienced SARS-COV-2 infection. However, more detailed studies are still needed to determine the stability and neutralizing properties of these antibodies.

Supplementary Information The online version contains supplementary material available at https://doi.org/10.1007/s00284-022-02800-0.

Acknowledgements We would like to thank Eshragh Translators Network for English language editing.

Author Contributions RJ and MHE analyzed the results and edited the manuscript with equal conceptualization. $\mathrm{ZY}$ and $\mathrm{PN}$ performed the study. RC, EB, MD, and NT collected data. All the authors confirmed and approved the final manuscript.

Funding This study was financially supported by Shahroud University of Medical Sciences (Grant No. 9929).
Data Availability All data and materials will be provided on request from the corresponding author.

\section{Declarations}

Conflict of interest There is no conflict of interest to declare that are relevant to the content of this article.

Ethical Approval and Consent to Participate Approval was obtained from the Ethics Committee of Shahroud University of Medical Sciences (Approval ID: IR.SHMU.REC.1398.077).

\section{References}

1. Figueiredo-Campos P, Blankenhaus B, Mota C, Gomes A, Serrano M, Ariotti S et al (2020) Seroprevalence of anti-SARS-CoV-2 antibodies in COVID-19 patients and healthy volunteers up to 6 months post disease onset. Eur J Immunol 50(12):2025-2040

2. Zhang G, Nie S (2020) Longitudinal Change of SARS-Cov2 antibodies in patients with COVID-19 Guoxin Zhang, Shuke Nie, Zhaohui Zhang, Zhentao Zhang

3. Zhang W, Du R-H, Li B, Zheng X-S, Yang X-L, Hu B et al (2020) Molecular and serological investigation of 2019-nCoV infected patients: implication of multiple shedding routes. Emerg Microbes Infect 9(1):386-389

4. Li T, Lu H, Zhang W (2020) Clinical observation and management of COVID-19 patients. Emerg Microbes Infect 9(1):687-690

5. Yongchen Z, Shen H, Wang X, Shi X, Li Y, Yan J et al (2020) Different longitudinal patterns of nucleic acid and serology testing results based on disease severity of COVID-19 patients. Emerg Microb Infect 9(1):833-836

6. Wu F, Wang A, Liu M, Wang Q, Chen J, Xia S, et al (2020) Neutralizing antibody responses to SARS-CoV-2 in a COVID-19 recovered patient cohort and their implications

7. Ibarrondo FJ, Fulcher JA, Goodman-Meza D, Elliott J, Hofmann C, Hausner MA et al (2020) Rapid decay of anti-SARSCoV-2 antibodies in persons with mild Covid-19. N Engl J Med 383(11):1085-1087

8. Wang S, Te-hui WC, Sakhatskyy PV, Huang S, Lawrence JM, $\mathrm{Cao} \mathrm{H}$ et al (2005) Identification of two neutralizing regions on the severe acute respiratory syndrome coronavirus spike glycoprotein produced from the mammalian expression system. J Virol 79(3): 1906-1910

9. Liu L, To KK-W, Chan K-H, Wong Y-C, Zhou R, Kwan K-Y et al (2020) High neutralizing antibody titer in intensive care unit patients with COVID-19. Emerg Microbes Infect 9(1):1664-1670

10. Ma H, Zhao D, Zeng W, Yang Y, Hu X, Zhou P, et al (2020) Decline of SARS-CoV-2-specific IgG, IgM and IgA in convalescent COVID-19 patients within 100 days after hospital discharge. Science China Life Sci 1-4

11. Liu A, Wang W, Zhao X, Zhou X, Yang D, Lu M et al (2020) Disappearance of antibodies to SARS-CoV-2 in a-COVID-19 patient after recovery. Clin Microbiol Infect 26(12):1703-1705

12. Seow J, Graham C, Merrick B, Acors S, Pickering S, Steel KJ et al (2020) Longitudinal observation and decline of neutralizing antibody responses in the three months following SARS-CoV-2 infection in humans. Nat Microbiol 5(12):1598-1607

13. Wajnberg A, Amanat F, Firpo A, Altman DR, Bailey MJ, Mansour $\mathrm{M}$ et al (2020) Robust neutralizing antibodies to SARS-CoV-2 infection persist for months. Science 370(6521):1227-1230

14. De Biasi S, Lo Tartaro D, Meschiari M, Gibellini L, Bellinazzi C, Borella R et al (2020) Expansion of plasmablasts and loss of 
memory B cells in peripheral blood from COVID-19 patients with pneumonia. Eur J Immunol 50(9):1283-1294

15. Ellebedy A, Turner J, Kim W, Kalaidina E, Goss C, Rauseo A, et al (2020) SARS-CoV-2 infection induces long-lived bone marrow plasma cells in humans

16. Sun B, Feng Y, Mo X, Zheng P, Wang Q, Li P et al (2020) Kinetics of SARS-CoV-2 specific IgM and IgG responses in COVID-19 patients. Emerg Microbes Infect 9(1):940-948

17. Zhang B, Zhou X, Zhu C (2020) Immune phenotyping based on neutrophil-tolymphocyte ratio and $\mathrm{IgG}$ predicts disease severity and outcome for patients with COVID-19. Front Mol Biosci

18. Qun S, Wang Y, Chen J, Huang X, Guo H, Lu Z et al (2020) Neutrophil-to-lymphocyte ratios are closely associated with the severity and course of non-mild COVID-19. Front Immunol 11:2160

19. Zhang B, Zhou X, Zhu C, Song Y, Feng F, Qiu Y et al (2020) Immune phenotyping based on the neutrophil-to-lymphocyte ratio and IgG level predicts disease severity and outcome for patients with COVID-19. Front Mol Biosci 7:157

20. Kaneko N, Kuo H-H, Boucau J, Farmer JR, Allard-Chamard $\mathrm{H}$, Mahajan VS et al (2020) Loss of Bcl-6-expressing T follicular helper cells and germinal centers in COVID-19. Cell 183(1):143-157

21. Cañete PF, Vinuesa CG (2020) COVID-19 makes B cells forget, but $\mathrm{T}$ cells remember. Cell 183(1):13-15

Publisher's Note Springer Nature remains neutral with regard to jurisdictional claims in published maps and institutional affiliations. 